\title{
An exploration study to detect important factors influencing internet marketing: A case study of food industry
}

\author{
Shadan Vahabzadeh ${ }^{\mathrm{a}}$, Jamshid Salehi Sadaghiani ${ }^{\mathrm{b}}$, Mehdi Asgarielo ${ }^{\mathrm{a} *}$ and Maryam Jabbarzadeh ${ }^{\mathrm{a}}$
}

${ }^{a}$ Department of Business Management, North Branch, Islamic Azad University, Tehran, Iran

${ }^{b}$ Department of Management, Allameh TabaTabayi University Tehran, Iran

\section{H R O N I C L E}

Article history:

Received January 18, 2013

Received in revised format 10 May 2013

Accepted May 152013

Available online

May 182013

Keywords:

Internet marketing

Food industry

Internal/external factors

Ease of use

\begin{abstract}
A B S T R A C T
Internet marketing plays an important role on profitability of organizations, it can build a bridge between customers and business owners and anyone could purchase products and services through internet. In this paper, we present an empirical investigation to detect important factors influencing internet marketing on Iranian food industry, named Shahrvand. The proposed study selects 280 out of 1040 managers who were involved in this industry during the year of 2012. Structural equation modeling has been performed to detect important factors including internal/external factors, ease of use and electronic marketing. Cronbach alphas have been calculated for these four items were mostly above 0.80 , which validated the overall questionnaire of the survey. The results indicate that among internal factors, knowledge management, organizational culture and resources influence on acceptance of internet marketing, while these factors do not show any meaningful impact on ease of use. In addition, external factors including trend on market growth, competition and infrastructure influence on ease of use and acceptance of internet marketing but infrastructure and competition do not impact on ease of internet marketing.
\end{abstract}

(C) 2013 Growing Science Ltd. All rights reserved.

\section{Introduction}

Internet marketing plays an essential role on today's business enterprises and many firms have recently chosen internet as primary method for promoting their products (Tikkanen et al., 2009). Sehhat (2012) investigated the effect of five factors namely awareness from the site, site attractiveness, promotional effectiveness, effectiveness and shopping perspective and effectiveness and loyalty on the success of electronic marketing. They implemented a multi regression function and their results confirmed that all five mentioned factors influenced the sales of e-marketing, significantly. Marketing planning in food industry is getting more important since the quality of products are involved with people's healthcare and loyalty plays essential role on this event (Espejel et al., 2008).

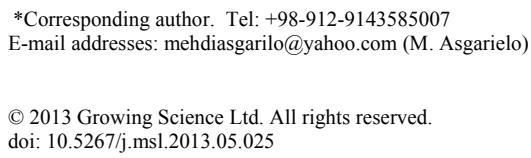


Azad (2012). investigated important factors influencing purchasing from chains. They surveyed essential factors, influencing customers to purchase more from one of well-known food market operating in capital city of Iran named Shahrvand. The results indicated that perception was the most important item. Years of experience was the most important item in their survey followed by effect of color and working hours. Diversity of services was also another factor, which played the most important role followed by quality of services. In addition, fidelity and brand were other most important factors and the name of store and risk are in lower degree of importance.

$\mathrm{Wu}$ et al. (2011) investigated the effect of store image and service quality on brand image and purchase intention for private label brands. Lalali Naini et al. (2012) studied the effects of various factors on advertising by examining the simultaneous impacts of exposure to the advertisement, type of the media, creativity in advertisements and being informative. They collected the necessary data from one of the chain supermarkets of Tehran called "Shahrvand"; and concentrated on the effectiveness of four independent variables and the effects of customers' needs on encouraging consumers to purchase. They reported some positive relationship between some factors and intention to purchase and emphasized that using creativity in advertisements, however dominate the effects on this issue. The marketing and advertisement environment were considered as dynamic and the work concentrated only on some of the more effective factors. They also explained that producers could be more successful in choosing the best way to promote their goods and services by following the proposed model.

Kim et al. (2010) investigated the impact of consumer perception on web advertisements and motivation factors to purchase in the online shopping. Wu et al. (2008) investigated the effects of the atmospheric factors of online storefront Environment design: an empirical experiment in Taiwan. Park and Lee (2009) considered the impact of information direction, website reputation and eWOM effect by looking into the effects of product type.

In this paper, we present an empirical investigation to detect important factors influencing internet marketing on Iranian food industry, named Shahrvand. The organization of this paper first considers the structure of different hypotheses in section 2. Section 3 presents details of the results and concluding remarks are given in the last to summarize the contribution of the paper.

\section{The proposed method}

The proposed method of this paper considers different factors including internal/external, ease of use, etc. on the success of electronic marketing. Fig. 1 shows details of the structure of the proposed method.

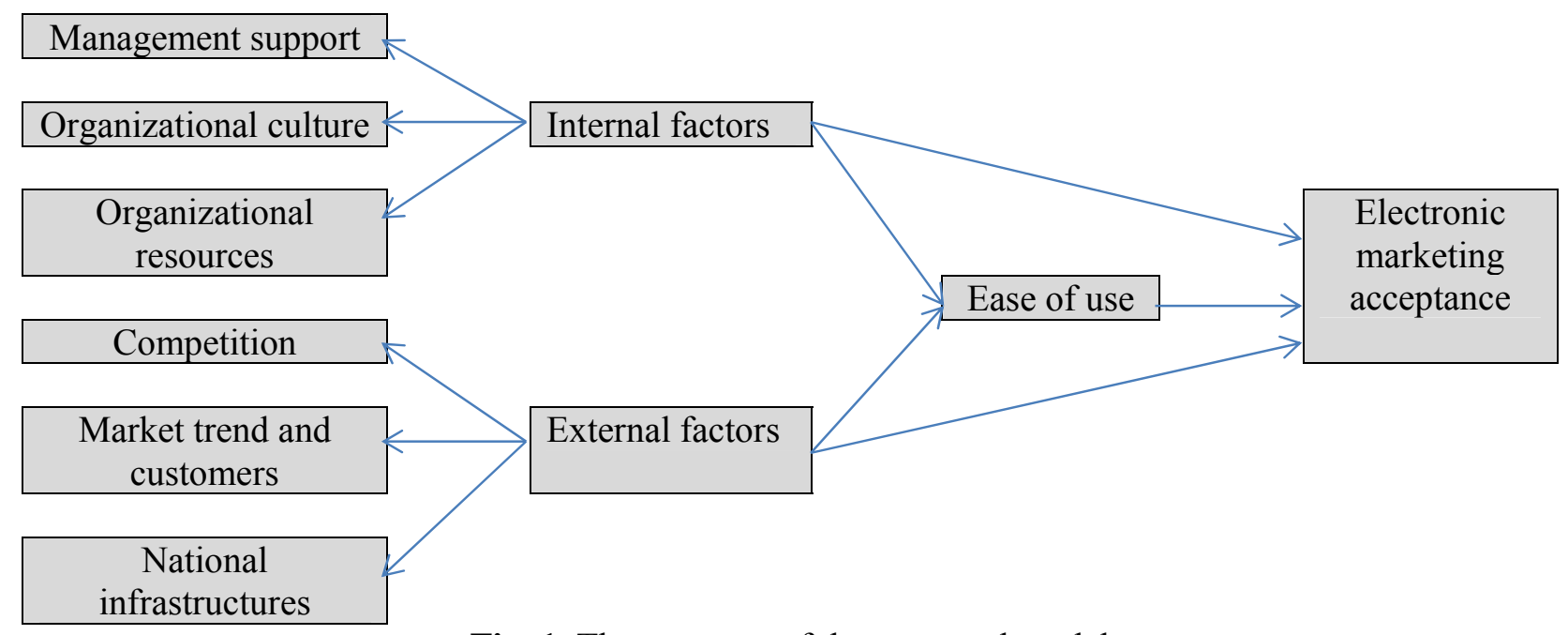

Fig. 1. The structure of the proposed model 
Based on the structure of Fig. 1 we consider the following five hypotheses,

1. Internal factors influence electronic marketing acceptance.

2. External factors influence electronic marketing acceptance.

3. Internal factors influence ease of use of electronic marketing acceptance.

4. External factors influence ease of use of electronic marketing acceptance.

5. Ease of use influences on electronic marketing acceptance.

The proposed study designed a questionnaire in Likert scale (Likert, 1932) and distributed among some selected managers of the proposed food chain, Shahrvand, in city of Tehran, Iran. The sample size is calculated as follows,

$$
n=\frac{N \times z_{\alpha / 2}^{2} \times p \times q}{\varepsilon^{2} \times(N-1)+z_{\alpha / 2}^{2} \times p \times q},
$$

where $N$ is the population size, $p=1-q$ represents the yes/no categories, $z_{\alpha / 2}$ is CDF of normal distribution and finally $\varepsilon$ is the error term. Since we have $p=0.5, z_{\alpha / 2}=1.96$ and $N=1040$, the number of sample size is calculated as $n=280$. Cronbach Alpha has been used as a measure to validate the questionnaire and Table 1 shows details of our results for various questions of the survey.

\section{Table 1}

The summary of Cronbach alpha

\begin{tabular}{llcccc}
\hline Variable & Component & Q. & \# of Q. & Initial $\alpha$ & Final $\alpha$ \\
\hline \multirow{3}{*}{ Internal factors } & Management support & $1-6$ & 6 & 0.744 & 0.789 \\
& Organizational culture & $7-10$ & 4 & 0.788 & 0.839 \\
& Organizational resources & $11-14$ & 4 & 0.796 & 0.758 \\
\hline \multirow{3}{*}{ External factors } & Competition & $15-18$ & 4 & 0.737 & 0.890 \\
& Market trend and customers & $19-21$ & 3 & 0.703 & 0.839 \\
& National infrastructures & $22-25$ & 4 & 0.819 & 0.921 \\
\hline Ease of use & - & $26-29$ & 4 & 0.906 & 0.853 \\
Electronic acceptance & - & $30-34$ & 5 & 0.734 & 0.872 \\
\hline Total & - & $1-34$ & 34 & 0.863 & 0.954 \\
\hline
\end{tabular}

The results of Table 1 indicate that all Cronbach alphas (Cronbach, 1951) are well above the minimum acceptable levels. Next, we present details of our results based on the implementation of structural equation modeling (SEM) and using LSREL software package.

\section{The results}

In this section, we present details of our findings on implementation of SEM. Fig. 2 shows details of our findings,

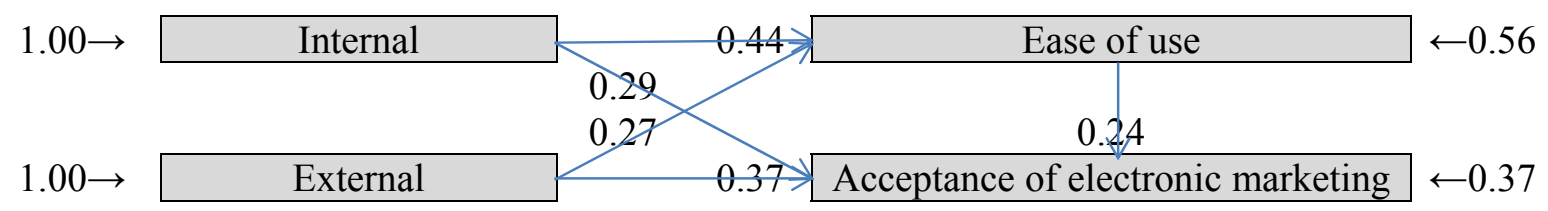

Fig. 2. The summary of the results of SEM among different components (Standard values) 


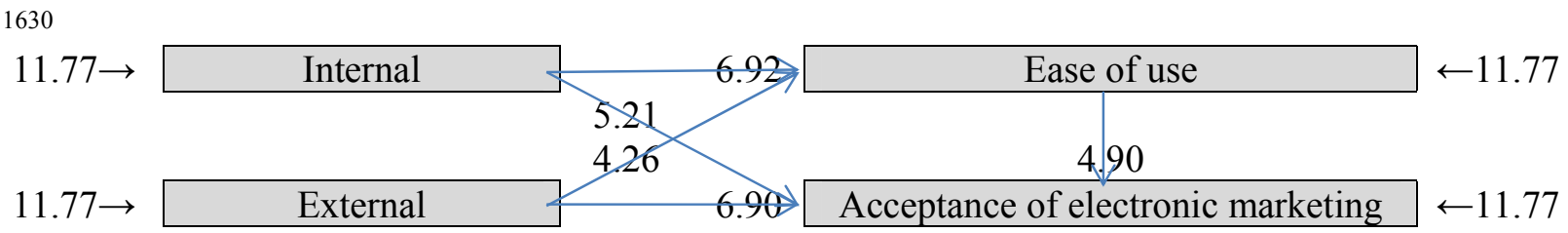

Fig. 3. The summary of the results of SEM among different components (t-student values)

In order to have a better understating on the nature of different factors, we summarize the results in Table 2 as follows,

Table 2

The summary of the coefficients for the implementation of SEM on the main factors

\begin{tabular}{llrcc}
\hline Independent Variable & Dependent variable & Direct & Indirect & Total \\
\hline Internal factors & Ease of use & 0.44 & & 0.44 \\
& Acceptance of electronic marketing & 0.29 & 0.11 & 0.40 \\
\hline External factors & Ease of use & 0.27 & & 0.27 \\
& Acceptance of electronic marketing & 0.37 & 0.07 & 0.44 \\
\hline Ease of use & Acceptance of electronic marketing & 0.24 & & 0.24 \\
\hline
\end{tabular}

As we can observe from the results of Table 2, two components of internal and external factors have positive and meaningful impact on ease of use as well as acceptance of electronic marketing. In addition, ease of use also influences acceptance of electronic marketing, positively. Table 3 shows details of the statistical observation associated with our survey.

Table 3

The summary of statistical observations for the implementation of SEM on the main factors

\begin{tabular}{llccc}
\hline $\begin{array}{l}\text { Independent } \\
\text { Variable }\end{array}$ & Dependent variable & Coefficient & t-value & Results \\
\hline Internal factors & Ease of use & 0.44 & 6.92 & Confirmed \\
& Acceptance of electronic marketing & 0.29 & 5.21 & Confirmed \\
\hline \multirow{2}{*}{ External factors } & Ease of use & 0.27 & 4.26 & Confirmed \\
& Acceptance of electronic marketing & 0.37 & 6.90 & Confirmed \\
\hline Ease of use & Acceptance of electronic marketing & 0.24 & 4.90 & Confirmed \\
\hline
\end{tabular}

Based on the results of Tables 3, we can confirm that all five hypotheses have been confirmed when the level of significance is five percent.

\subsection{The results of testing sub-hypotheses}

We first examine the effects of three components of internal factors including management support, organizational culture and organizational resources on ease of use as well as acceptance of electronic marketing and Table 4 shows details of our findings.

\section{Table 4}

The summary of the effects of internal components

\begin{tabular}{llrrrr}
\hline Item & Sub-component & \multicolumn{2}{c}{ Ease of use } & \multicolumn{2}{c}{ Electronic acceptance } \\
& & Coefficient & Sig. & Coefficient & Sig. \\
\hline 1 & Management support & 0.137 & 0.024 & 0.248 & 0.000 \\
2 & Organizational culture & 0.263 & 0.000 & 0.428 & 0.000 \\
3 & Organizational resources & 0.375 & 0.000 & 0.181 & 0.001 \\
\hline
\end{tabular}


The results of Table 4 clearly show that all three components could impact ease of use as well as electronic acceptance of marking when the level of significance is five percent.

Now we study the impacts of three components of external factors including management support, organizational culture and organizational resources on ease of use as well as acceptance of electronic marketing and Table 5 shows details of our findings.

Table 5

The summary of the effects of external components

\begin{tabular}{llcccc}
\hline Item & Sub-component & \multicolumn{2}{c}{ Ease of use } & \multicolumn{2}{c}{ Electronic acceptance } \\
& & Coefficient & Sig. & Coefficient & Sig. \\
\hline 1 & Management support & 0.388 & 0.000 & 0.611 & 0.000 \\
2 & Organizational culture & 0.097 & 0.127 & 0.149 & 0.004 \\
3 & Organizational resources & 0.229 & 0.000 & 0.99 & 0.024 \\
\hline
\end{tabular}

The results of Table 4 clearly show that two components, management support and organizational culture, had positive relationship with ease of use as well as electronic acceptance of marking when the level of significance is five percent. However, our survey did not provide any meaningful relationship between organizational culture and the mentioned two variables.

\section{Conclusion}

We have performed an empirical investigation on different factors on acceptance of electronic marketing in one of Iranian food chains located in city of Tehran, Iran. The proposed study of this paper has implemented structural equation modeling for this study and the results have concluded that internal and external factors could impact acceptance of internet marketing on food industry. Based on the results of this survey, we may hope that internet marketing will become more popular as government establishes better infrastructures inside country. In fact, the recent effort of having intranet service could significantly help increase domestic connections.

\section{References}

Azad, N. (2012). Investigating important factors influencing purchasing from chains. Management Science Letters, 2(3), 805-810.

Cronbach, L. J. (1951). Coefficient alpha and the internal structure of tests. Psychometrika, 16(3), 297-334.

Espejel, J., Fandos, C., \& Flavián, C. (2008). Consumer satisfaction: A key factor of consumer loyalty and buying intention of a PDO food product. British Food Journal, 110(9), 865-881.

Ghose, K. (2009). Internal brand equity defines customer experience. Direct Marketing: An International Journal, 3(3), 177-185.

Kim, J. U.K., Kim, W.J. \& Park, S. Ch. (2010). Consumer perception on web advertisements and motivation factors to purchase in the online shopping. Computers in human behavior, 1208-1222.

Lalali Naini, S., Shafia, M \& Nazari, N. (2012). Examining different factors in effectiveness of advertisement. Management Science Letters, 2(3), 811-818.

Likert, R. (1932). A Technique for the Measurement of Attitudes. Archives of Psychology, 140, 1-55.

Park, C \& Lee T.M. (2009). Information direction, website reputation and eWOM effect: A moderating role of product type. Journal of Business Research, 62(1), 61-66.

Sehhat, S. (2012). An empirical survey to measure the impact of different factors on the success of electronic marketing. Management Science Letters, 2(6), 2187-2192.

Tikkanen, H., Hietanen, J., Henttonen, T. \& Rokka, J. (2009). Exploring virtual worlds: success factors in virtual world marketing. Management Decision, 47(8), 1357-1381. 
Wu, C.S., Cheng, F.F. \& Yen, D.C. (2008).The atmospheric factors of online storefront Environment design: an empirical experiment in Taiwan. Information \& Management, 45(7), 493-498.

Wu, P.C.S., Yeh, G.Y.Y., \& Hsiao, C.R. (2011). The effect of store image and service quality on brand image and purchase intention for private label brands. Australasian Marketing Journal, 19, $30-39$. 